\title{
Original
}

\section{CD146/MCAM Surface Marker for Identifying Human Periodontal Ligament- derived Mesenchymal Stem Cells}

\author{
Yoko Saito $^{1)}$, Eri Watanabe ${ }^{2)}$, Kotoe Mayahara ${ }^{3,4}$, Nobukazu Watanabe ${ }^{2)}$, Masakazu Morokuma ${ }^{1}$, \\ Keitaro Isokawa ${ }^{4,5}$, Noriyoshi Shimizu ${ }^{3,4)}$ and Masaki J. Honda ${ }^{4,5)}$ \\ 1) Nihon University Graduate School of Dentistry, Tokyo, Japan \\ 2) Laboratory of Diagnostic Medicine, The Institute of Medical Science, The University of Tokyo, Tokyo, Japan \\ 3) Department of Orthodontics, Nihon University School of Dentistry, Tokyo, Japan \\ 4) Dental Research Center, Nihon University School of Dentistry, Tokyo, Japan \\ 5) Department of Anatomy, Nihon University School of Dentistry, Tokyo, Japan \\ (Accepted for publication, December 11, 2012)
}

\begin{abstract}
Identification of the specific subset of periodontal ligament-derived mesenchymal stem cells (PDLSCs) will permit the development and improvement of current periodontal regeneration therapy. A popular approach for the isolation of a subset of PDLSCs would be to use cell surface markers to identify these cells, which are effectively enriched in order to isolate stem cells. The CD146 marker is most commonly used to isolate PDLSCs from human periodontal ligament tissues (hPDL). Previous studies have shown that CD146-positive (CD146+) cells possess potencies of high self-renewal and multi-lineage differentiation. However, the capability and potency of mesenchymal stem cells (MSCs) in hPDL-derived CD146-negative (CD146-) cells have not been well established.

In this study, CD146+ and CD146- cells were isolated from hPDL, and their properties, including their MSCs potential, were characterized. hPDL was obtained from healthy premolars $(\mathrm{n}=10)$ extracted for orthodontic reasons. Flow cytometry analysis revealed that the average proportion of CD146+ cells was about $50 \%$. An approximately $20 \%$ fraction of cells with the highest CD146 expression was sorted as CD146+ cells and an approximately $20 \%$ fraction with the lowest CD146 expression was sorted as CD146- cells using fluorescenceactivated cell sorting. Cell cultures were assessed for their colony-forming efficiency, proliferation and differentiation into osteoblasts, adipocytes and chondrocytes. Approximately $20 \%$ of CD146+ cells had replicative potential and formed single-cell colonies. The colony-forming efficiency of CD146+ cells was approximately twofold higher than for CD146- cells. Cell proliferation measured by cell-cycle analysis and cell counting showed that the proliferative potential of CD146+ cells was higher than that of CD146- cells. Cell differentiation potential in vitro was determined by real-time PCR and cell staining with alkaline phosphatase and Alizarin Red S for osteogenic differentiation, Oil Red O for adipogenic differentiation, and Alcian Blue for chondrogenic differentiation. The levels of osteogenic and adipogenic differentiation were significantly higher in CD146+ cells than in CD146- cells under appropriate conditions. The level of glycosaminoglycan and gene expression of cartilage oligomeric matrix protein in CD146- cell pellets were higher than in CD146+ cell pellets. These results suggest that CD146+ cells possess bi-potent differentiation potential whereas CD146- cells possess unipotent differentiation potential.
\end{abstract}

Key words: CD146/MCAM, CD146 negative cells, CD146 positive cells, Periodontal ligament, Periodontal ligament-derived mesenchymal cells

\section{Introduction}

Periodontal disease is one of the major concern in dentistry because it causes the loss of periodontal tissue, resulting in tooth loss that can cause both functional and aesthetic problems for patients ${ }^{1}$. Once the periodontal ligament tissue (PDL) and alveolar bone are destroyed, it is clinically difficult to recover and reconstruct these three-dimensional tissues because the precise

Corresponding to: Dr. Masaki Honda, 1-8-13 Kanda-Surugadai Chiyodaku, Tokyo 101-8310 Japan; Tel: + 81-3-3219-8121; Fax: +81-3-32198319; E-mail: honda.masaki@nihon-u.ac.jp mechanisms that govern this disease and the regenerative processes that restore the lost tissues have not been fully characterized. Many new approaches have been used to facilitate the regeneration of lost or diseased periodontal tissue ${ }^{2)}$, but so far, none of these treatments has provided consistently predictable outcomes.

Previous studies have led us to speculate that the developing PDL, as well as the mature PDL, contain undifferentiated progenitor cells that are believed to play an important role in the repair of damaged periodontium ${ }^{3,4)}$. The developing PDL retains the potential to differentiate into the cells that constitute the PDL, 
such as osteoblasts, cementoblasts and fibroblasts ${ }^{5-7)}$. The specific key factors required for the maturation from undifferentiated cells to fully differentiated functional cells have not been elucidated.

Human PDL-derived mesenchymal stem cells (PDLSCs) were first identified by Seo and $\mathrm{Shi}^{8}$ and were isolated from adult normal impacted third molars. PDLSCs were characterized as highly proliferative cells that were capable of self-renewal, multipotent differentiation in vitro and had the capacity to generate PDL-like structures in vivo ${ }^{8}$. Immunocytochemical staining showed that cultured PDLSC expressed both STRO-1 and CD146 as early mesenchymal progenitor markers ${ }^{8,9)}$. CD146 is one marker that has been employed for the identification of MSCs in PDL cell populations ${ }^{10)}$. CD146 is also known as the melanoma cell adhesion molecule (MCAM) or cell surface glycoprotein, MUC18, and is currently used as a marker for the endothelial cell lineage ${ }^{11)}$. Putative PDLSCs that express the CD146 are located predominantly in the perivascular area ${ }^{12)}$. Collectively, previous studies have been mainly focused on CD146-positive (CD146 $\left.{ }^{+}\right)$ cells within PDL, that have the characteristics of mesenchymal stem cells (MSCs), whereas there is no data on the MSC-like characteristics of CD146 cells. Only one study ${ }^{13)}$ has compared the MSC-like characteristics of $\mathrm{CD} 146^{+}$cells and unsorted cells. This study demonstrated that STRO $-1^{+} / \mathrm{CD} 146^{+}$cells are characterized by high self-renewal and multi-lineage differentiation potential and that unsorted heterogeneous PDL cells do not possess MSC-like characteristics. The possibility that MSClike characteristics exist in PDL-derived CD146- cells remains equivocal.

From the standpoint of cell transplantation therapy for PDL regeneration, further characterization in the properties of PDLSCs is required. Identification of a specific subset of PDLSCs would expand the current periodontal regeneration therapy ${ }^{14,15)}$. A popular approach to isolate subsets of stem cell populations uses cell surface markers and fluorescence-activated cell sorting (FACS). We previously reported a CD271 $1^{+}$MSC population sorted from deciduous dental pulp ${ }^{16}$. This CD271 $1^{+}$MSC population showed the characteristics of more immature cells in the CD271- MSC population within dental pulp-derived mesenchymal stem cell (DPMSCs) ${ }^{16}$. To date, no transplantation studies using CD146 markers in PDL cell populations have been carried out although many studies on the transplantation of unsorted PDL heterogeneous cells has been reported over the last decade ${ }^{17,18)}$. Since any single specific PDLSCs marker is absent, the use of a combination of cell surface markers is necessary. The scarcity of data on CD146- cells stimulated us to characterize this cell population.

In this study, we characterized and compared the properties of $\mathrm{CD} 146^{+}$and $\mathrm{CD} 146^{-}$cells, which were isolated from human PDL cells. Our results indicate that $\mathrm{CD} 146^{+}$cells have bi-potent differentiation potential and CD146 cells remain uni-potent differentiation potential.

\section{Materials and Methods}

\section{Cell cultures}

In this study, ten human PDL tissue specimens (hPDL) were collected from healthy premolars that were extracted from patients aged 11-36 years for orthodontic reasons $(n=10$; two male and eight female donors, average age of 20 years, Table 1 ). The study conformed to the guidelines of the Declaration of Helsinki and the experimental protocol was reviewed and approved by the Ethics Committee at Nihon University School of Dentistry. Informed consent was obtained from all patients prior to donation of the tissue. The PDL was mechanically removed from the middle of the tooth-root surface using surgical scalpels. To exclude contamination from the gingival and apical tissues, the tissue obtained from the coronal and apical regions of the tooth-root was avoided. Tissue fragments were placed in $35-\mathrm{mm}$ tissue culture dishes (Falcon, Lincoln Park, NJ, USA) in alpha-minimal essential medium ( $\alpha$-MEM; Wako Pure Chemical Industries, Ltd., Osaka, Japan) supplemented with $20 \%$ fetal bovine serum (FBS; Nichirei Biosciences Inc., Tokyo, Japan) and 1\% antibiotics (Pen-Strep; GIBCO-Life Technologies, Grand Island, NY, USA) at $37^{\circ} \mathrm{C}$ in a $95 \%$ air $/ 5 \% \mathrm{CO}_{2}$ incubator. When the cells that grew out from the explants had reached pre-confluence, they were harvested and seeded on a 100-mm culture dish (Falcon). All cells were used between the second and third passage in culture.

\section{RNA isolation and reverse transcription-polymerase chain reaction}

The hPDL cells were rinsed twice with PBS and total RNA was extracted using RNAiso Plus (Takara Bio Inc., Shiga, Japan) according to the manufacturer's protocol. Following extraction with chloroform (Wako), RNA was precipitated with isopropanol (Wako), rinsed with 75\% ethanol (Wako), and redissolved in RNase-free water. The RNA concentration was determined using the Nano Drop1000 (Thermo Fisher Scientific Inc., Yokohama, Kanagawa, Japan).

Reverse-transcription from total RNA was performed using Superscript III ${ }^{\circledR}$ reverse transcriptase (Invitrogen, Carlsbad, CA, USA) according to the manufacturer's protocol. A reaction mixture containing $1 \mu \mathrm{g}$ of total RNA, $1 \mu \mathrm{L}$ of random primers (Takara Bio Inc.), $1 \mu \mathrm{L}$ of dNTP mixture $(10 \mathrm{mM})$ and distilled water in a total volume of $13 \mu \mathrm{L}$, were mixed and pre-incubated at $65^{\circ} \mathrm{C}$ for $5 \mathrm{~min}$. After placing on ice for $1 \mathrm{~min}$, the incubated sample was mixed with $1 \mu \mathrm{L}$ of Superscript III ${ }^{\circledR}$ reverse-transcriptase (200 units $/ \mu \mathrm{L}$ ), $1 \mu \mathrm{L}$ of $0.1 \mathrm{M}$ dithiothreitol, $1 \mu \mathrm{L}$ of RNaseOUT ${ }^{\mathrm{TM}}$ Ribonuclease Inhibitor, $4 \mu \mathrm{L}$ of $5 \times$ First-Stand Buffer and then incubated at $25^{\circ} \mathrm{C}$ for $5 \mathrm{~min}, 50^{\circ} \mathrm{C}$ for $60 \mathrm{~min}$, and $70^{\circ} \mathrm{C}$ for 15 min. Using the cDNA as a template, semi-quantitative polymerase chain reaction (sqPCR) was carried out under the following 
Yoko Saito et al.: CD146 Marker for PDL

conditions: annealing temperature of $57^{\circ} \mathrm{C}$ (Col-I, Col-III, ColXII, Periostin, Mohawk, $\beta$-actin), $60^{\circ} \mathrm{C}$ (Runx2, OSX, ALP, BSP, OC, Col-XVIII, EphrA4, Scleraxis), and $62^{\circ} \mathrm{C}$ (Tenomodulin). After 30 (Col-I, Col-III, Col-XII, Periostin, Mohawk, $\beta$-actin) and 35 (Runx2, OSX, ALP, BSP, OC, Col-XVIII, EphrA4, Scleraxis, Tenomodulin) cycles, samples were analyzed by electrophoresis on a $1.5 \%$ agarose gel, and were visualized by ethidium bromide staining. The primer sequences for sqPCR are described in Table 2.

\section{Quantitative real-time polymerase chain reaction (Real-time PCR)}

Aliquots of the cDNA samples $(2 \mu \mathrm{L})$ were subjected to realtime PCR using SYBR Green PCR Master Mix (Takara). Realtime PCR was performed in a thermal cycler $\left(\mathrm{C} 1000^{\mathrm{TM}}\right.$ Thermal cycler, Bio-Rad Laboratories, Hercules, CA, USA), and the data were analyzed using CFX Manager ${ }^{\mathrm{TM}}$ Software (ver.2.1). Realtime PCR cycling conditions used were: 40 cycles at $95^{\circ} \mathrm{C}$ for $5 \mathrm{~s}$ and $60^{\circ} \mathrm{C}$ for $20 \mathrm{~s}$. Each real-time PCR reaction was performed in triplicate, and the levels of mRNA expression were calculated and normalized to the level of human $\beta$-actin mRNA.

\section{Phenotype analysis}

We analyzed the expression of a panel of nine cell-surface markers on donor cells. The phenotype of the PDL cells obtained by explant culture was identified using standard FACS techniques to assay typical cell surface markers including APC-CD34 (hematopoietic stem cell marker), FITC-CD45 (leukocyte marker), FITC-CD44, PE-CD73, APC-CD90, PE-CD146, PE-CD271, Alexa Fluor 647-SSEA4 (BD Biosciences, Franklin, NJ, USA), FITC-STRO-1 (Santa Cruz Biotechnology, Santa Cruz, CA, USA). Briefly, the hPDL cells at the second passage were cultured and the cells were harvested with $0.05 \%$ trypsin-EDTA (GIBCO) when they reached $90 \%$ confluence. Harvested cells were resuspended in $300 \mu \mathrm{L}$ of PBS with $1 \%$ mouse BSA and incubated for $20 \mathrm{~min}$ on ice to block non-specific binding of antibodies. They were then incubated with the primary antibodies or control IgG (BD Biosciences, San Jose, CA, USA) on ice for $30 \mathrm{~min}$. After staining, cells were washed with PBS and resuspended in $300 \mu \mathrm{L}$ of FACS buffer for flow cytometric analysis using BD FACS Aria (BD Biosciences, San Jose, CA, USA). Dead cells were identified by staining with propidium iodide (PI; $1 \mu \mathrm{g} / \mathrm{mL}$; Sigma-Aldrich, St. Louis, Mo, USA) and were excluded from the surface epitope analysis. FCS (Flow Cytometry Data File Format Standards) data were analyzed using FlowJo software (Treestar, San Carlos, CA, USA).

\section{Fluorescence-activated cell sorting (FACS)}

The performance of $\mathrm{CD} 146^{+}$and CD146- cells was analyzed by harvesting hPDL cells at $80 \%$ confluency and the PDL cells were four-color stained with a combination of the following directly-coupled mouse anti-human antibodies: anti-CD44-FITC, anti CD146-PE (BD), anti-CD90-APC (BD) and anti-CD45-Alexa Flow 405 (invitrogen) in $1 \mathrm{~mL}$ of PBS on ice for $30 \mathrm{~min}$ in the dark. Thereafter, four-color stained cells were isolated into a $\mathrm{CD} 146^{+} / \mathrm{CD}_{4} 4^{+} / \mathrm{CD} 90^{+} / \mathrm{CD} 45^{-}$cell population $\left(\mathrm{CD} 146^{+}\right.$cells $)$and a CD146 $/ \mathrm{CD}^{2} 4^{+} / \mathrm{CD}^{\circ} 0^{+} / \mathrm{CD} 45^{-}$cell population (CD146 cells) using FACS (BD FACS Aria, BD Biosciences).

\section{Colony-forming efficiency assay}

CD146+ and CD146- cells were separately seeded at 100 cells/ well in a six-well plate and cultured in growth medium for 7 days. The cells were fixed with $10 \%$ neutral buffered formalin and newly formed colonies were visualized using $0.1 \%(\mathrm{w} / \mathrm{v})$ toluidine blue (Sigma-Aldrich) staining. Aggregates of more than 50 cells were scored as colonies using light microscopy. The colony-forming efficiency was calculated as the number of colonies relative to the total number of seeded cells in each well.

\section{Cell cycle analysis}

$\mathrm{CD} 146^{+}$and CD146- cells were cultured in 100-mm culture dishes $\left(1 \times 10^{5}\right.$ cells/dish $)$ in growth medium for 3 days, and cell cycle analysis was performed using Click-iT ${ }^{\mathrm{TM}}$ EdU Flow Cytometry Assay Kits (Invitrogen/Molecular Probes, Eugene, OR, USA) according to the manufacturer's instructions. In brief, cultured cells were treated for $1 \mathrm{~h}$ with $10 \mathrm{mM}$ EdU (5-ethynyl2'-de-oxyuridine), which is a nucleoside analog of thymidine and is incorporated into DNA during active DNA synthesis. EdUincorporated cells were fixed with paraformaldehyde for $15 \mathrm{~min}$, washed once with BSA/PBS buffer and permeabilized with a saponin-based buffer for $30 \mathrm{~min}$. The cells were then washed once, treated with the click-reaction mixture containing Alexa Fluor 488 azide for $30 \mathrm{~min}$, washed again, and resuspended in PBS buffer. Next, to measure the DNA content of the cells was measured by staining with CellCycle 488-red in 1\% BSA/PBS for 30 min. After staining, the cells were washed twice with PBS and then cell cycle analysis was performed using a FACS Aria (BD Biosciences).

\section{Cell proliferation assays}

Cell proliferation was determined by viable cell counting. A total of $1 \times 10^{4}$ PDLs were plated in six-well plates and cultured at specific days. After 2, 4, 9 and 16 days, the cells were detached with $0.05 \%$ trypsin and the total number of cells was measured using a microscope counting chamber (hemocytometer).

\section{Differentiation into mesodermal lineage cells}

The hallmark of MSCs is their ability to differentiate into mesodermal lineage cells. Therefore, we undertook studies to differentiate both $\mathrm{CD} 146^{+}$and CD146- cells into osteogenic, adipogenic, and chondrogenic lineages. 
A

$\mathrm{B}$

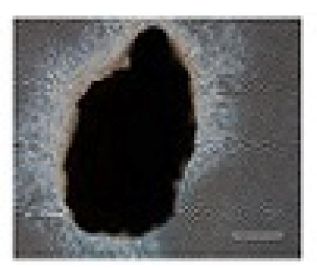

hPDL Cells

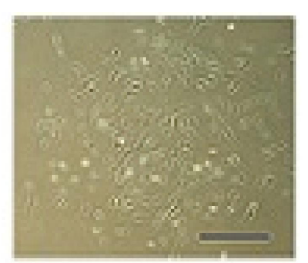

三

C
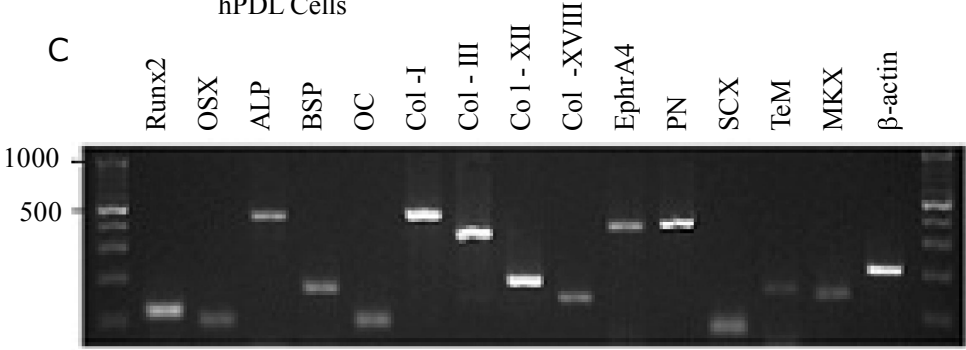

Figure 1. Cell culture and semi quantitative polymerase chain reaction (sqPCR) analysis of human periodontal ligament cells (hPDL cells)

(A) Cells that grew from the explant PDL were observed by phase-contrast microcopy. Bar: $500 \mu \mathrm{m}$. (B) mRNA was extracted from cultured cells at the third passage in growth medium. Bar: $500 \mu \mathrm{m}$. (C) The expression levels of osteoblastic markers (Runx2, OSX, ALP, BSP, OC, Col I, and Col III), PDL and tenogenic markers (Col XII, Col XVIII, EphrA4, PN, SCX TeM and MKX) were measured using expression of the $\beta$-actin gene as the reference.

\section{Osteogenesis}

Osteogenic differentiation of hPDL cells were induced as previously described ${ }^{19}$. Briefly, CD146 ${ }^{+}$and CD146- cells were sorted and passaged once in six-well culture plates $\left(1 \times 10^{4}\right.$ cells/ well) with growth medium consisting of $\alpha$-MEM supplemented with $10 \%$ heat inactivated FBS, $1 \%$ Pen-Strep. After reaching $80 \%$ confluence, the medium was replaced with osteogenic induction medium; growth medium supplemented with $1 \mathrm{nM}$ dexamethasone (Sigma-Aldrich), $20 \mathrm{mM} \beta$-glycerophosphate (Sigma-Aldrich), and $50 \mu \mathrm{g} / \mathrm{mL}$ L-ascorbate phosphate (Wako). The cells were maintained with fresh osteogenic induction medium every 2 days for the indicated period for following analysis.

Cells were cultured in osteogenic medium or growth medium for 3 days and the mRNA was then extracted. Real-time PCR was used to analyze the level of mRNA expression of Runx2, BSP, ALP and OSX. (Table 2)

After culture for indicated days, cells were fixed $10 \%$ neutral buffered formalin for $15 \mathrm{~min}$. Subsequently, cultures were washed twice with PBS and stained with alkaline phosphatase (ALP) activity staining solution, pH 9.5 (NBT/BCIP ready-to-use tablets; Roche Diagnostics, Penzberg, Germany) for 15 min or a saturated solution of Alizarin Red-S ( $\mathrm{pH} 4.0$ ) for $5 \mathrm{~min}$. Cells were washed with distilled water, and examined under a light microscope or an EPSON scanner, GT-X800 (EPSON, Tokyo, Japan).

$\mathrm{Ca}^{2+}$ accumulation was determined by measuring $\mathrm{Ca}^{2+}$ uptake into the cell culture at 21 days. The culture supernatant was removed and cells were washed with PBS, $1 \mathrm{M} \mathrm{HCl}$ solution was added to each well and $500 \mu \mathrm{L}$ of distilled water was added to each well. The amount of $\mathrm{Ca}^{2+}$ was determined using the Calcium E-test (Wako) according to the manufacturer's instructions.

\section{Adipogenesis}

$\mathrm{CD}_{146^{+}}$and CD146- cells were cultured in six-well culture plates $\left(5 \times 10^{3}\right.$ cells/well $)$ with growth medium. After reaching $90 \%$ confluence, the medium was replaced with adipogenic induction medium: $\alpha$-MEM supplemented with $10 \%$ FBS, $1 \mu \mathrm{M}$
Table 1. Proportion of CD146 ${ }^{+}$cell fraction in cultured PDL cells obtained from 10 patients

\begin{tabular}{ccccccc}
\hline Number & Age & Sex & $\begin{array}{c}\text { CD146 } \\
(\%)\end{array}$ & $\begin{array}{c}\text { Culture } \\
\text { period } \\
\text { (days) }\end{array}$ & $\begin{array}{c}\text { CD146+ } \\
\text { passage } \\
(\%)\end{array}$ \\
\hline 1 & 14 & M & 64.8 & 60 & - & \\
2 & 35 & F & 60.6 & 45 & - & \\
3 & 11 & F & 36.2 & 38 & - & \\
4 & 19 & M & 47.3 & 61 & - & \\
5 & 36 & F & 35.9 & 34 & - & \\
6 & 27 & F & 33.0 & 30 & - & \\
7 & 16 & F & 54.3 & 31 & $90.1 \pm 7.6(\mathrm{P} 5)$ \\
8 & 13 & F & 64.0 & 36 & $8.53 \quad(\mathrm{P} 6)$ \\
9 & 11 & F & 46.2 & 28 & $92.0 \quad(\mathrm{p} 5)$ \\
10 & 21 & F & 40.1 & 36 & - & \\
\hline
\end{tabular}

Average $20.3 \pm 9.4 \quad-\quad 49.1 \pm 11.8 \quad 39.9 \pm 11.8$

M:male F: female

dexamethasone (Sigma-Aldrich), $170 \mathrm{nM}$ insulin (Sigma-Aldrich), $0.2 \mathrm{mM}$ indomethacin (Sigma-Aldrich), and $0.45 \mathrm{mM}$ isobutylmethylxanthine (Sigma-Aldrich) and the cells were cultured for 21 days ${ }^{19)}$. Lipid vacuole formation in the adipogenic cultures was determined by Oil Red O staining on day 21 . The cells were fixed with $10 \%$ neutral buffered formalin for $15 \mathrm{~min}$, rinsed with distilled water, and incubated with $60 \%$ isopropanol for $1 \mathrm{~min}$. The cells were stained with the Oil Red O working solution ( $30 \mathrm{~mL}$ of $3 \mathrm{mg} / \mathrm{mL}$ Oil Red O/isopropanol stock solution and $20 \mathrm{~mL}$ of distilled water) for $15 \mathrm{~min}$ at $37^{\circ} \mathrm{C}$. The cultures were observed with phase contrast microscopy (ECLIPSE TS100, Nikon, Tokyo, Japan). mRNA was extracted for gene expression analysis from both cell populations cultured in adipogenic or growth medium for 7 days. Real-time PCR was used to analyze mRNA expression of PPAR $\gamma$, ADD1 and adiponectin. (Table 3)

\section{Chondrogenesis}

The chondrogenic potential of CD146 ${ }^{+}$and CD146- cells was examined in pellet cultures. Cell pellets were collected in centrifuge tube $\left(2.5 \times 10^{5}\right.$ cells/tube $)$ with growth medium. After 
Yoko Saito et al.: CD146 Marker for PDL

Table 2. Sequence of primer pairs for reverse transcriptionpolymerase chain reaction (PCR) and real-time PCR used in osteogenic potential analysis

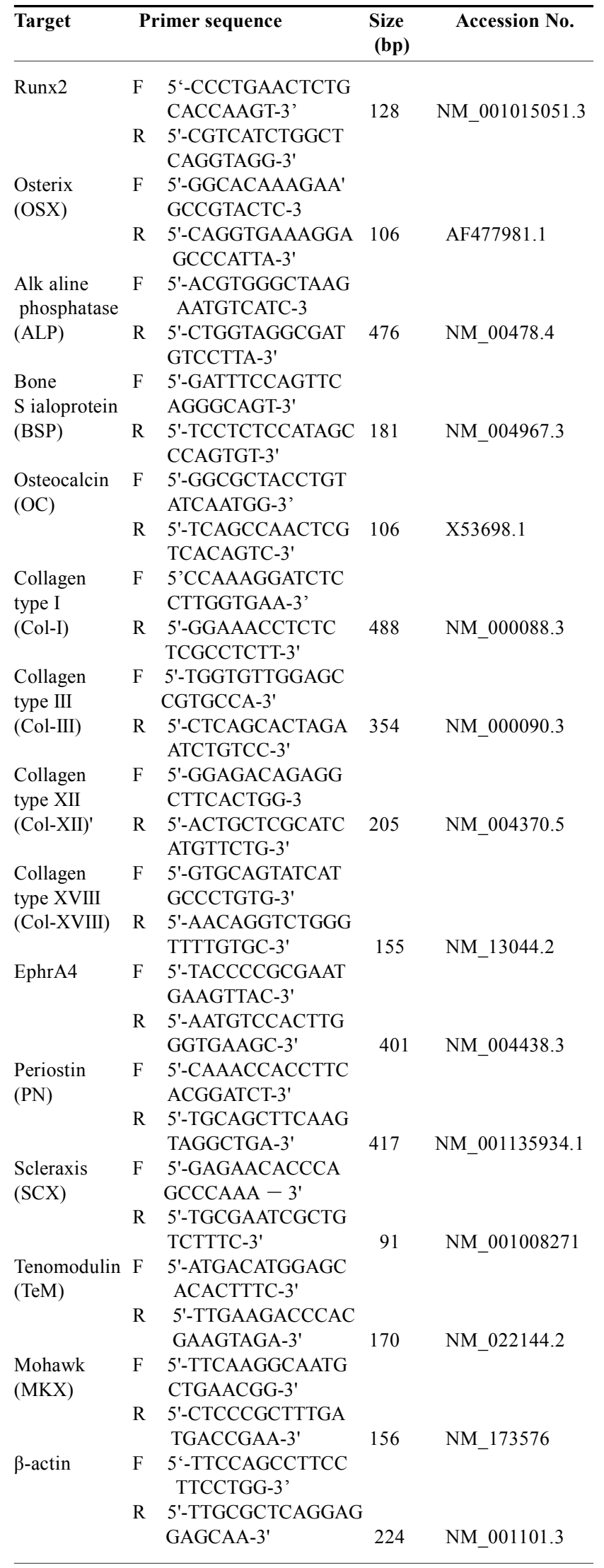

F: Forward R: Reverse
Table 3. Primer sequences on adipogenic potential analysis for real-time PCR

\begin{tabular}{|c|c|c|c|c|}
\hline \multirow{3}{*}{$\begin{array}{l}\text { Target } \\
\text { PPAR } \gamma\end{array}$} & \multicolumn{2}{|c|}{ Primer sequence } & \multirow{2}{*}{$\begin{array}{l}\text { Size } \\
\text { (bp) }\end{array}$} & \multirow{2}{*}{$\begin{array}{l}\text { Accession } \\
\text { No. }\end{array}$} \\
\hline & $\mathrm{F}$ & 5'-TCAGGTTTGGGC & & \\
\hline & & GGATGC-3’ & & \\
\hline & $\mathrm{R}$ & 5'-TCAGCGGGAAG & 147 & NM_015863.4 \\
\hline & & GACTTTATGTATG-3' & & \\
\hline \multirow[t]{3}{*}{ ADD1 } & $\mathrm{F}$ & 5'-AGCGAGCACTG & & \\
\hline & & AACTGTGTG-3' & & \\
\hline & $\mathrm{R}$ & $\begin{array}{l}\text { 5'-GGAGAAGCTGTA } \\
\text { GGCAGGAG-3' }\end{array}$ & 143 & NM_004176.4 \\
\hline \multirow[t]{3}{*}{ Adiponectin } & $F$ & 5'-TCTGTTTCCCA & & \\
\hline & & CCTCACCTGA-3' & & \\
\hline & $\mathrm{R}$ & $\begin{array}{l}\text { 5'-CAGGACGTCATCATA } \\
\text { GAACCACTT-3' }\end{array}$ & 107 & NM_001177800.1 \\
\hline \multirow[t]{2}{*}{$\beta$-actin } & $\mathrm{F}$ & $\begin{array}{l}\text { 5`-TTCCAGCCTTCC } \\
\text { TTCCTGG-3' }\end{array}$ & & \\
\hline & $\mathrm{R}$ & $\begin{array}{l}\text { 5'-TTGCGCTCAGGA } \\
\text { GGAGCAA-3' }\end{array}$ & 224 & NM_001101.3 \\
\hline
\end{tabular}

F: Forward R: Reverse

Table 4. Primer sequences on chondrogenic potential analysis for real-time PCR

\begin{tabular}{|c|c|c|c|c|}
\hline Target & & rimer sequence & $\begin{array}{l}\text { Size } \\
\text { (bp) }\end{array}$ & $\begin{array}{l}\text { Accession } \\
\text { No. }\end{array}$ \\
\hline Cartilage & $\mathrm{F}$ & 5'-GACAGTGATGGC & & \\
\hline oligomeric & & GATGGTATAGG-3 & & \\
\hline matrix protein & $\mathrm{R}$ & 5'-TCACAAGCATCT & & \\
\hline (COMP) & & CCCACAAAGT-3' ' & 104 & NM_000095.2 \\
\hline \multirow[t]{4}{*}{$\beta$-actin } & $\mathrm{F}$ & 5'-TTCCAGCCTTCC & & \\
\hline & & TTCCTGG-3' & & \\
\hline & $\mathrm{R}$ & 5'-TTGCGCTCAGGA & 224 & NM_001101.3 \\
\hline & & GGAGCAA-3' & & \\
\hline
\end{tabular}

F: Forward R: Reverse

2 days in culture, the growth medium was replaced with $\alpha$-MEM supplemented with $1 \mu \mathrm{M}$ dexamethasone, $50 \mu \mathrm{g} / \mathrm{mL}$ L-ascorbate phosphate (Wako), 1× Insulin-Transferrin-Selenium-A (GIBCOLife Technologies, Grand Island, NY, USA), $10 \mathrm{ng} / \mathrm{mL}$ recombinant human TGF- $\beta 3$ (R\&D Systems, Inc., Minneapolis, MN, USA) as chondrogenic differentiation medium for 28 days. Control groups were exposed to $\alpha$-MEM and $1 \times$ InsulinTransferrin-Selenium-A for 28 days.

The microscopic structure of cells was examined after cell pellets were fixed in 10\% neutral buffered formalin, dehydrated in a series of ethanol, embedded in paraffin, and cut into $7 \mu \mathrm{m}$ sections. After deparaffinization of the sections they were stained with either hematoxylin and eosin (H\&E) or Alcian Blue. The glycosaminoglycan (GAG) content was also determined using a sulfated GAG assay kit (Biocolor Ltd., County Antrim, UK). DNA content was determined using a fluorescent DNA quantification kit (Bio-Rad Laboratories, Hercules, CA, USA). Cells were cultured in chondrogenic medium or growth medium for 7 days. Real-time PCR was used to analyze mRNA expression of COMP. 

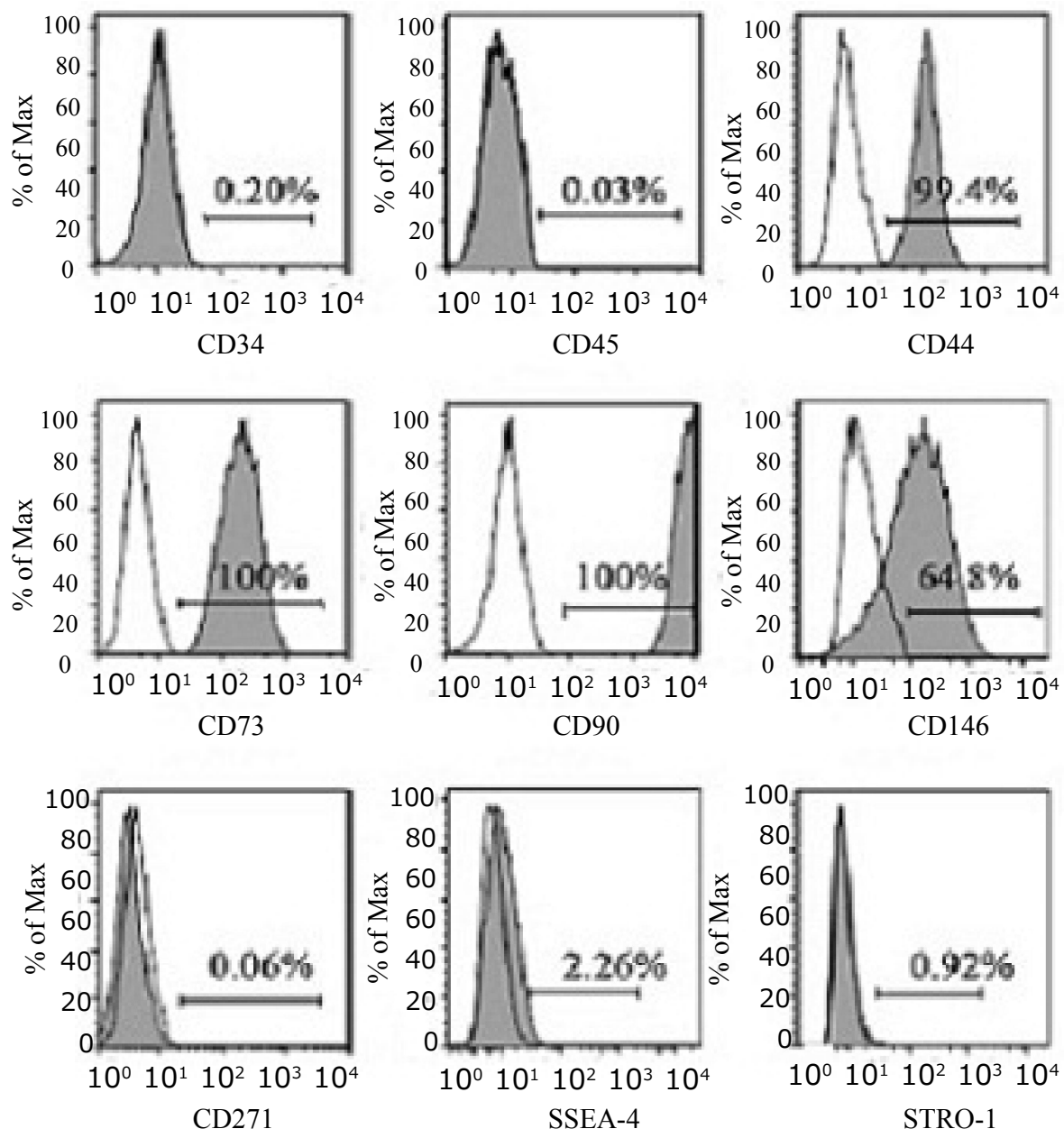

Figure 2. FACS analysis of the immunophenotype of hPDL cells Human PDL cells positively stained for CD44, CD73, CD90, CD146, and SSEA-4, but were negative for CD34, CD45, CD271, and STRO-1. The white histograms show nonspecific staining and the black histograms show specific staining for the indicated markers.

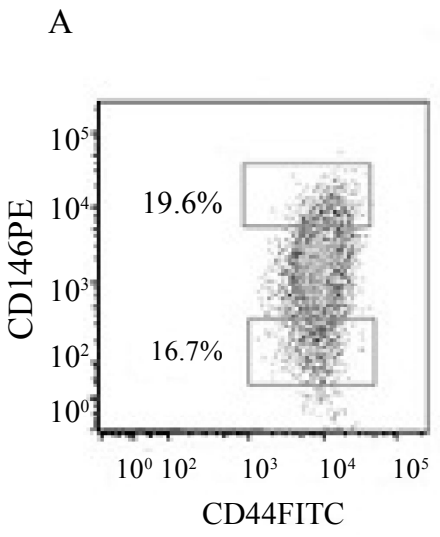

B
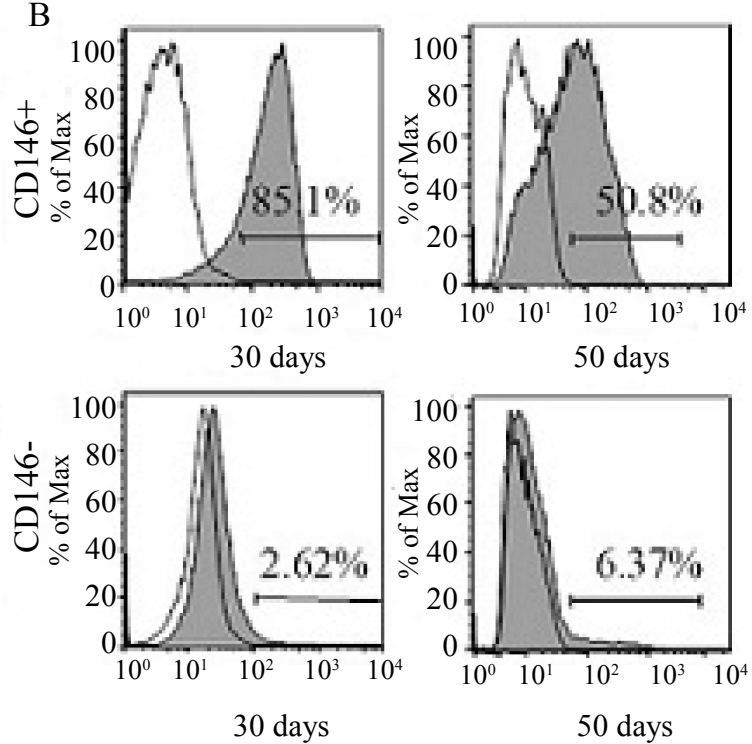

Figure 3. Stability of CD146 expression in CD146 ${ }^{+}$and CD146 cells after long-term culture.

(A) After the exclusion of $\mathrm{CD}_{45}+$ CD90-/CD44- cells from the hPDL cell population they were sorted into two cell populations with higher and lower CD146 expression, respectively. The upper and lower boxes represent $\mathrm{CD} 44^{+} \mathrm{CD} 45^{-}$ $\mathrm{CD} 90^{+} \mathrm{CD} 146^{+}$cells and $\mathrm{CD} 44^{+}$ CD45- CD 90 $0^{+} \mathrm{CD} 146^{-}$cells, respectively. (B) The stability of CD146 expression in $\mathrm{CD}_{146}{ }^{+}$and CD146- cells was examined after the cells were sorted, and expanded for 30 days or 50 days in vitro. Thereafter, expression of CD146 was analyzed by FACS again. The white histograms show nonspecific staining and the black histograms show specific staining for the indicated marker. 
(Table 4)

\section{Statistical analysis}

All statistical analyses were performed using EZR (Saitama Medical Center, Jichi Medical University (http://www.jichi.ac.jp/ saitama-sct/SaitamaHP.files/statmedEN. html ). Statistical differences were evaluated using Student's t-test, Welch twosample t-test and Steel-Dwass test. A $P$ value of less than 0.05 was considered statistically significant.

\section{Results \\ Characterization of hPDL cells}

In primary culture of a hPDL explant, spindle-shaped cells migrated away from the explant and these cells appeared high proliferative (Fig. 1A). mRNA levels of osteogenic and tenogenesis-related genes were analyzed by sqPCR at the third passage of cell population (Fig. 1B) that had been used in previous experiments ${ }^{20-22)}$. The mRNA expression of the osteogenic (Runx2, Osx, ALP, BSP, OCN, Col-I, Col-III) and tenogenic (Col-XII ColXVIII, EPHrA4, Periostin, Scleraxis, Tenomodulin and Mohawk) genes were all detected (Fig. 1C).

A panel of cell surface markers were assayed for their expression on hPDL cells (Fig. 2). The hematopoietic markers, CD34 and CD45 were negative, whereas common BMSC markers (CD44, CD73, CD90) were positive ( $>90 \%$ positive cells). The expression levels of CD271, STRO-1, and SSEA4 were low (Fig. 2).

CD146 has been used to identify or isolate the PDLSCs in PDL. Therefore, the proportion of CD146 ${ }^{+}$cells in PDL cells was also examined. While the expression of CD146 showed marked variability between donors, the average number of CD146 ${ }^{+}$cells was $49.1 \% \pm 12.4 \%$ in hPDL cells (Table 1 ).

\section{Stability of CD146 expression}

PDL cells were sorted into two cell populations with higher CD146 expression (19.6\%) (CD146+) and lower CD146 expression (16.7\%) (CD146), see Fig. 3-A. After sorting, the stability of CD146 expression in long-term culture and in the culture of seventh-passage cells was examined in growth medium. FACS analysis showed that the proportion of CD146 ${ }^{+}$cells was $85.1 \%$ at 30 days of culture and $50.8 \%$ at 50 days of culture with one passage. CD146 expression was also detected at a lower level in the CD146- cells (Fig. 3B). Surprisingly, in one donor out of ten, the initial cell samples sorted as CD146- showed a higher proportion of $\mathrm{CD}_{146^{+}}$cells alter (data not shown).

In contrast, after five or six passages ( $\mathrm{P} 5$ or $\mathrm{P} 6$ ), the proportion of $\mathrm{CD} 146^{+}$cells in the $\mathrm{CD} 146^{+}$cell population was over $90 \%$ in two samples but one out of three donors showed a much lower proportion of CD146 ${ }^{+}$cells $(8.5 \%)$ (Table 1$)$.

\section{Characteristics of CD146 ${ }^{+}$and CD146- cells}

\section{Clonogenic and growth potential}

The single cell-derived colony-forming efficiency and cell proliferation assay were successfully performed in five samples (Figs. 4 and 5). The colony-forming efficiency of CD146 ${ }^{+}$cells was found to be significantly higher at approximately twice that of CD146- cells in four samples (Fig. 4B). There was no significant difference in one sample (data not shown). Both cell populations possessed replicative potential.

Cell proliferation analysis showed that the growth potential of $\mathrm{CD} 146^{+}$cells was higher than that of CD146- cells at day 16 with a significant difference observed in four samples (Fig. 5A). Furthermore, cell cycle analysis showed that the $\mathrm{CD}_{146^{+}}$cell population contained a significantly higher percentage of cells in $\mathrm{S}$ and G2M phases than the CD146 cell population in two samples (Fig. 5B).

\section{Osteogenic differentiation potential}

The osteogenic differentiation potential of the CD146 and CD146- cells was determined at the indicated days by ALP and Alizarin Red-S staining. ALP activity clearly increased with time in both cell populations with or without differentiation-inducing medium. After 3 days of culture in the osteogenic medium CD146 cells showed more intense ALP activity than any other cells (Fig. $6 \mathrm{~A}) . \mathrm{CD} 146^{+}$cells in the osteogenic medium showed the formation of positive Alizarin Red-S-staining nodules after 14 days in culture and obvious accumulation of mineralized nodules in osteogenic medium at 21 days by phase-contrast microscopy. The accumulation of mineralized nodules in CD146- cells in osteogenic medium was barely discernible (Fig. 6B). Interestingly, both $\mathrm{CD} 146^{+}$and CD146- cells under growth medium condition did not accumulate $\mathrm{Ca}^{2+}$ in the culture medium even though ALP staining was clearly positive (Fig. 6B). To quantify mineral formation, the $\mathrm{Ca}^{2+}$ content of the culture was calculated. The mineral content dramatically increased and there was a significant difference in the $\mathrm{Ca}^{2+}$ content in osteogenic medium at 21 days (Fig. 6C).

Real-time PCR analysis demonstrated an increased expression of Runx2 and ALP in CD146 ${ }^{+}$cells compared with CD146- cells (Fig. 6D). The levels of expression of Runx2 and ALP mRNAs but not Osterix and BSP mRNAs were significantly higher $(P<$ 0.05) in $\mathrm{CD}_{146^{+}}$cells than in CD146- cells in osteogenic medium.

The stability of CD146 expression was examined in both cell populations under in both growth medium and osteogenic medium. The proportion of CD146 ${ }^{+}$cells in $\mathrm{CD} 146^{+}$cell population after osteogenic induction for 28 days was over $20 \%$ but the proportion of $\mathrm{CD} 146^{+}$cells in any other population was less than $6 \%$ (Fig. $7 \mathrm{~A})$.

\section{Adipogenic differentiation potential}

The accumulation of lipid vacuoles as determined by positive 


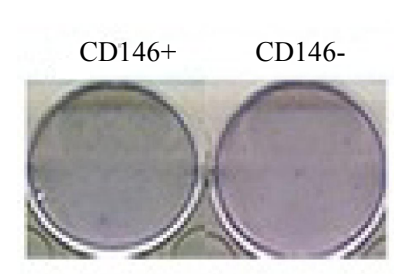

B

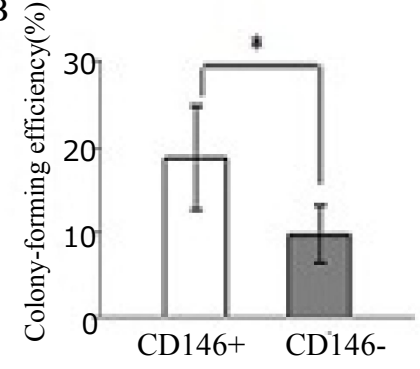

Figure 4. Colony-forming unit-fibroblast (CFU-F) assays The potential of clonogenic cell cluster formation was analyzed in $\mathrm{CD}_{146^{+}}$and $\mathrm{CD} 146^{-}$cells. (A) After the cells were incubated for 7 days they were then stained with $0.1 \%$ $(\mathrm{w} / \mathrm{v})$ toluidine blue. (B) The number of colonies in the cultures were counted $(n=5)$. Aggregates of more than 50 cells were scored as colonies. The colony-forming efficiency was calculated as the number of colonies standardized by the total number of seeded cells in each plate. Each bar indicates the mean \pm standard deviation (SD) in triplicate from five experiments $(* P<0.05)$

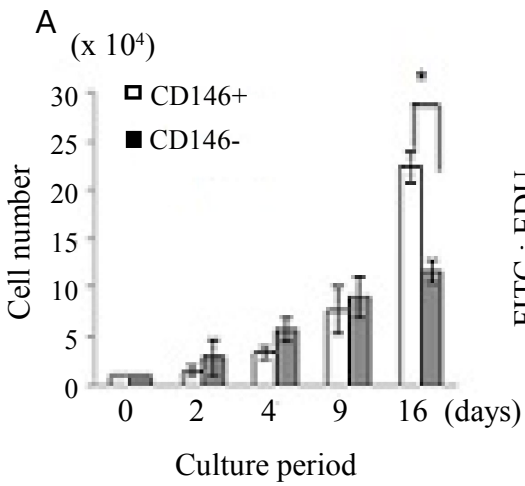

B

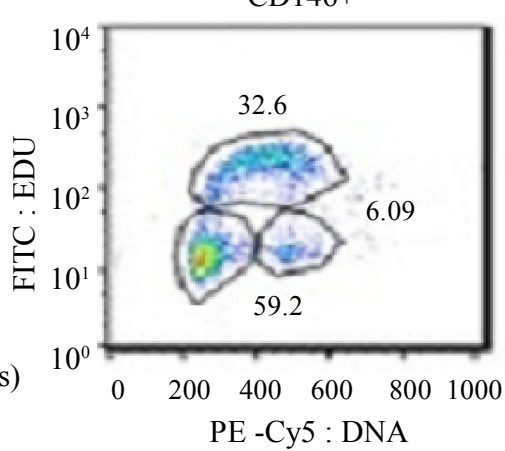

CD146-

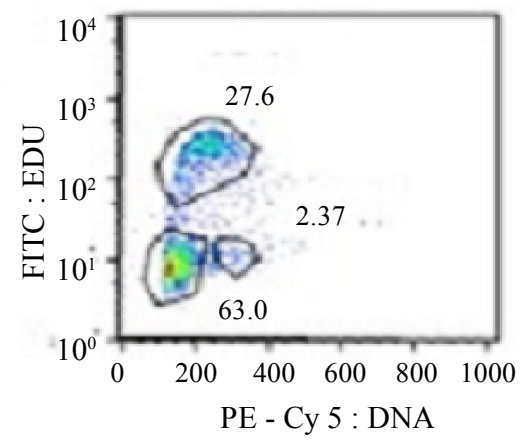

\begin{tabular}{lllllll}
\hline Number & \multicolumn{1}{c}{$\mathrm{S}$} & \multicolumn{2}{c}{$\mathrm{G} 2+\mathrm{M}$} & \multicolumn{2}{c}{$\mathrm{G} 1$} \\
\hline \multicolumn{4}{c}{$\mathrm{CD} 146+$} & CD146- & CD146+ \\
7 & 22.0 & 16.0 & 7.0 & 4.0 & 55.0 & 60.0 \\
9 & 32.6 & 27.6 & 6.09 & 2.37 & 59.2 & 63.0 \\
\hline
\end{tabular}

Figure 5. Proliferation and cell cycle progression (A) Cells were cultured in growth medium for 16 days and then the cell number was counted by hemocytometer at the indicated days. Each bar indicates the mean \pm standard deviation (SD) in triplicate from three experiments $\left({ }^{*} P<0.05\right)$. (B) Representative data of cell-cycle analysis is shown. Cells in logarithmic growth phase were treated with EdU for $1 \mathrm{~h}$. Cells were stained with Alexa Fluor 488 azide (y-axis, log scale) to detect EdU incorporation and with CellCycle 488-red to detect total DNA (x-axis, linear scale). The lower left box represents G1-phase cells, the upper box represents S-phase cells, and the lower right box represents $\mathrm{G} 2-\mathrm{M}$-phase cells. The numbers given in the boxes indicate the percentage of gated events. EdU analysis was performed twice and the table showed data from two experiments.
Table 5. Proportion of positive Oil Red O-staining cells

\begin{tabular}{ccc}
\hline & $\mathrm{CD}_{146^{+}(\%)}$ & $\mathrm{CD}^{+} 46^{-}(\%)$ \\
\hline 1 & 8.9 & 2.8 \\
2 & 7.7 & 0.0 \\
3 & 1.9 & 0.0 \\
4 & 4.0 & 5.0 \\
5 & 5.0 & 0.3 \\
\hline AV & $5.5 \pm 2.8^{*}$ & $1.6 \pm 2.2$ \\
\hline AV: Average \pm standard deviation & ${ }^{*} p<0.05$
\end{tabular}

Oil-Red O staining was observed within the cytoplasm in all $\mathrm{CD}_{146^{+}}$cell samples when subjected to adipogenic differentiation (Fig. 7A). Surprisingly, this positive staining was observed in three out of five CD146- cell donors (Table 5). The number of positive Oil-Red-O-staining cells was counted and the proportion of positive staining cells was calculated. The proportion of positive cells in the $\mathrm{CD} 146^{+}$cells was $5.5 \%$ with significantly difference observed in CD146- cells (1.6\%).

Real-time PCR analysis also demonstrated increased expression of an adipocyte-specific marker (adiponectin) and two adipocyte differentiation transcripts (ADD1 and PPAR $\gamma$ ) (Fig. 7B). In addition, the stability of CD146 expression was examined after adipogenic induction for 28 days. The proportion of CD146 cells in the $\mathrm{CD} 146^{+}$cell population cultured in adipogenic medium was greater than $20 \%$ but the proportion of CD $146^{+}$cells in any other cell population was less than $3 \%$ by FACS analysis (Fig. $8 \mathrm{~B}$ ).

\section{Chondrogenic differentiation potential}

To determine whether $\mathrm{CD} 146^{+}$and $\mathrm{CD} 146^{-}$cells are capable of differentiating into chondrogenic lineage cells, both cell populations were maintained in pellet cultures for 28 days. The newly synthesized glycosaminoglycan (GAG) component of cartilage-specific proteoglycan, showed positive Alcian Blue staining in both $\mathrm{CD} 146^{+}$and CD146- cell pellets that were cultured in chondrogenic induction medium (Fig. 9A). In contrast, noninduced $\mathrm{CD} 146^{+}$and $\mathrm{CD} 146^{-}$pellets displayed no staining of GAG. The GAG content in CD146- cells was compared to CD146 ${ }^{+}$cells cultured in chondrogenic induction medium for 28 days (Fig. 9B). Interestingly, the GAG level in CD146- pellets was significantly 
Yoko Saito et al.: CD146 Marker for PDL

A
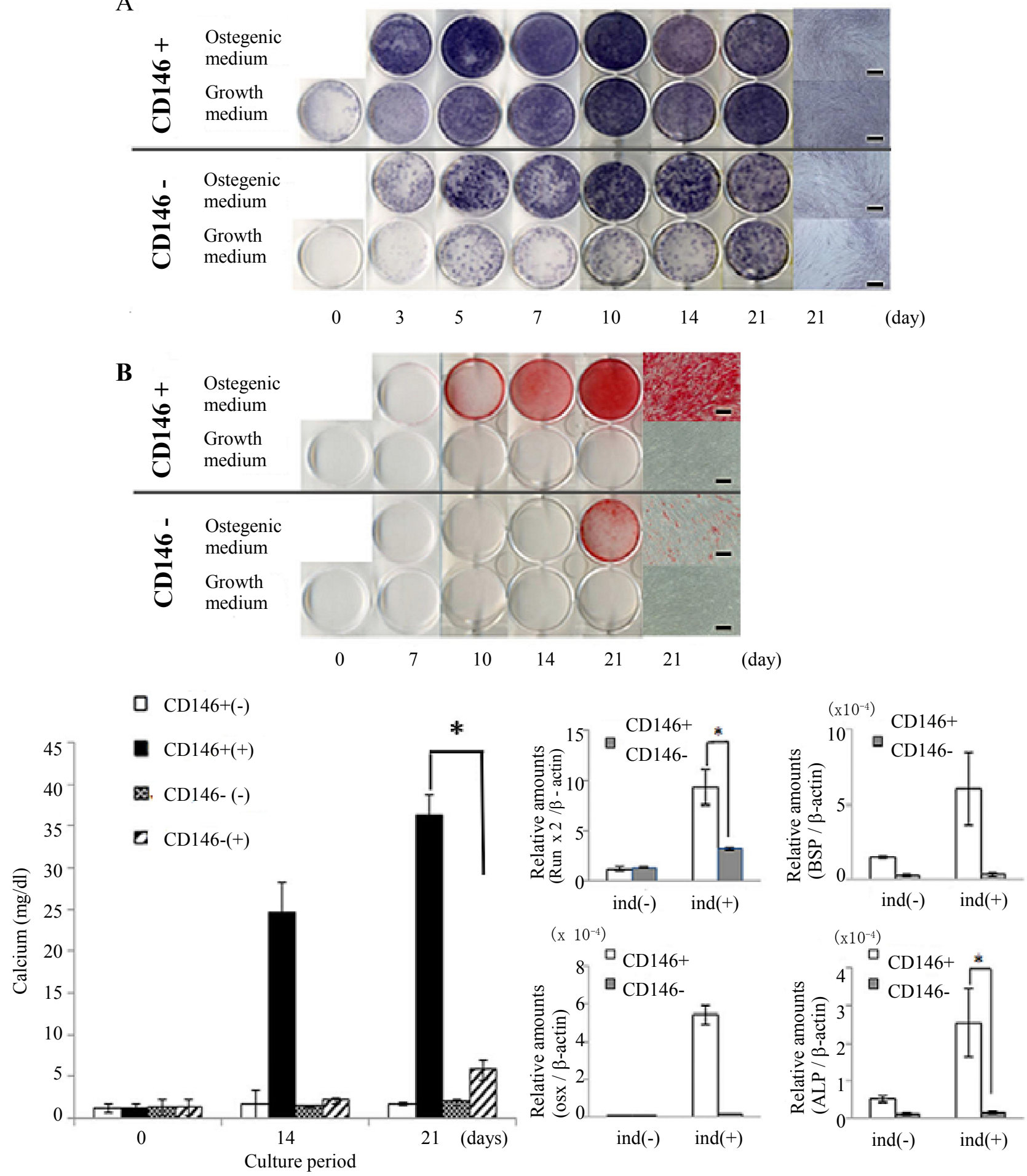

Figure 6. Osteogenic differentiation potential

After cells reached $80 \%$ confluence, growth medium was replaced with osteogenic medium for 21 days. ALP and Alizarin Red-S staining were performed at the indicated days. (A) ALP activity gradually increased with time in CD146 ${ }^{+}$and CD146 cells with or without osteogenic medium. The peak of ALP staining in CD146 ${ }^{+}$and CD146- cells with osteogenic substance was day 10 , while CD146 ${ }^{+}$and $\mathrm{CD}^{-} \mathrm{B}^{-}$cells under growth medium was day 21 . The stained cultures at day 21 were observed by phase-contrast microscopy. Bar: $250 \mu$ m. (B) No positively Alizarin Red-S staining cells were observed in the growth medium. At day 21, a small number of positively Alizarin Red-S staining cells were observed in the CD146- cell population. The stained cultures at day 21 were observed by phase-contrast microscopy. Bar: $250 \mu \mathrm{m}$. (C) The $\mathrm{Ca}^{2+}$ content of the cultures was measured. Each bar indicates the mean \pm standard deviation (SD). $\left(\mathrm{n}=4,{ }^{*} P<0.05\right)(\mathrm{D}) \mathrm{CD} 146^{+}$and CD146 cells were cultured in growth medium (ind (-)) or osteogenic medium (ind (+)) for 3 days and mRNAs were extracted. Real-time PCR was used to analyze mRNA expression of indicated osteogenic markers (Runx2, OSX, BSP, ALP). Each bar indicates the mean \pm standard deviation $\left(\mathrm{n}=3,{ }^{*} \mathrm{P}<0.05\right)$. 
A

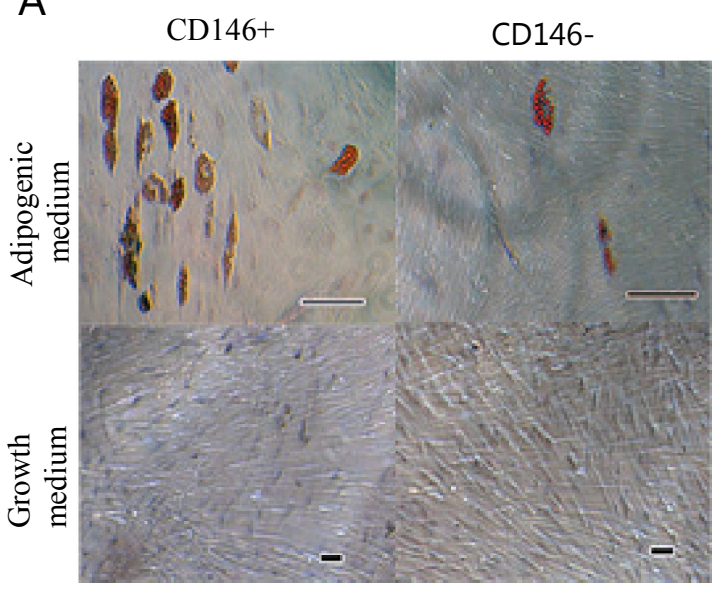

Figure 7. Adipogenic differentiation potential (A) $\mathrm{CD} 146^{+}$and $\mathrm{CD} 146^{-}$cells were cultured in six-well plates with growth medium before confluence. After reaching $90 \%$ confluence, cells were cultured with adipogenic medium for 21 days. Then Oil Red O staining was performed and the cells were observed by phasecontrast microscopy. Bar: $100 \mu \mathrm{m}$
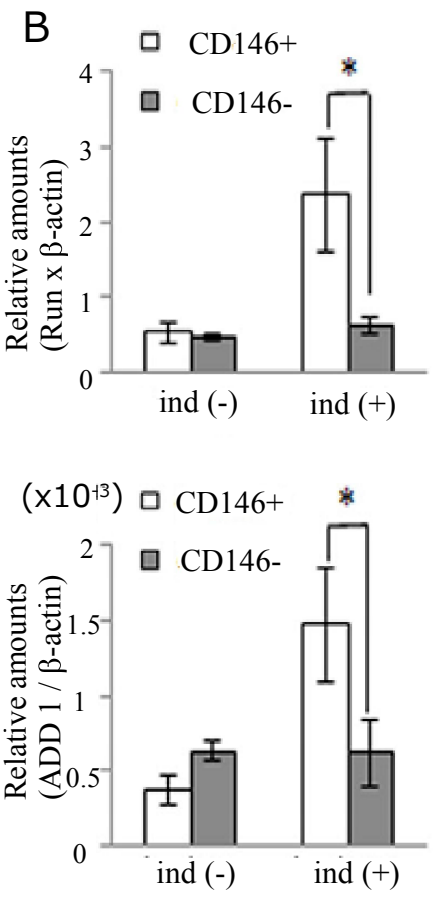

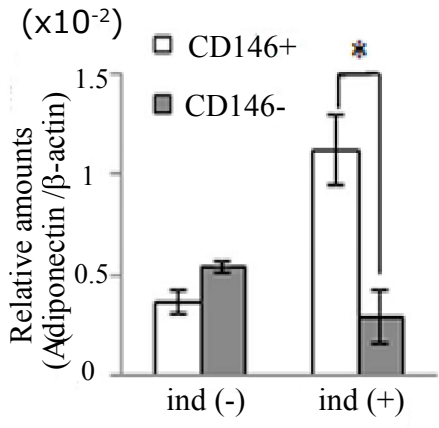

(B) Cells were cultured in growth medium (ind (-)) or adipogenic medium (ind $(+)$ ) for 3 days and mRNAs were extracted. Real-time PCR was used to analyze mRNA expression of the indicated adipogenic markers (PPAR $\gamma$, Adiponectin, ADD1). Each bar indicates the mean \pm standard deviation $(\mathrm{SD})\left(\mathrm{n}=3,{ }^{*} P<0.05\right)$.
A

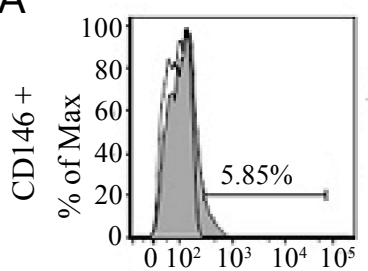

Crowth medium

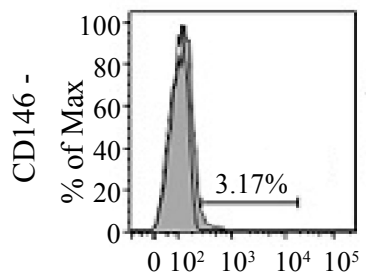

Crowth medium

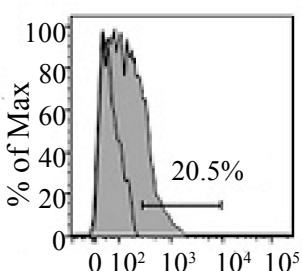

Ostegenic medium

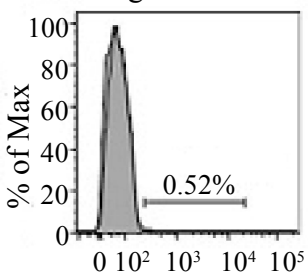

Ostegenic medium
B
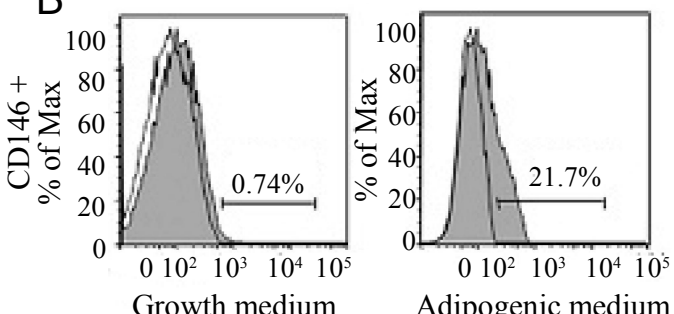

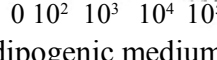
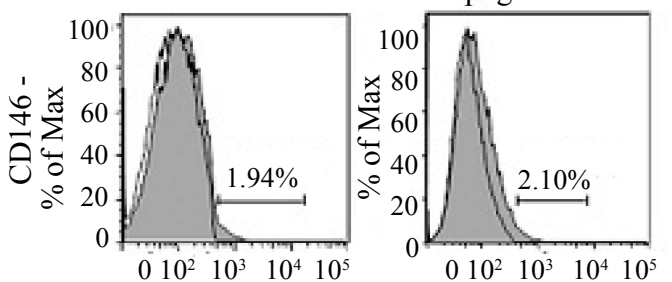

Growth medium

Adipogenic medium

Figure 8. Stability of CD146 expressions after osteogenic and adipogenic differentiation

CD146 expression was examined by FACS analysis in CD146 and CD146- cells after culturing the cells with either osteogenic medium or adipogenic medium for 21 days. The white histograms show nonspecific staining and the black histograms show specific staining for CD146. (A) The proportion of $\mathrm{CD} 146^{+}$cells were over $20 \%$ in the $\mathrm{CD} 146^{+}$cell population in osteogenic medium. (B) The proportion of CD146 ${ }^{+}$cells was also over $20 \%$ in the $\mathrm{CD} 146^{+}$cell population in adipogenic medium.

higher than for $\mathrm{CD} 146^{+}$pellets. Furthermore, gene expression of cartilage oligomeric matrix protein (COMP) as a glycoprotein in the CD146 cell pellet was also significantly higher than in the CD146 ${ }^{+}$cell pellet (Fig. 9C). There was no significant difference in gene expression for Sox9 and Col II (data not shown).

\section{Discussion}

Recent studies have shown that the transplantation of PDL cells may be essential for PDL regeneration ${ }^{23,24)}$. Significant bottlenecks for the clinical application of PDL cells are the generation of a standardized suitable cell subset and inadequate knowledge of the exact biological properties of PDL cells. Human PDLSCs have been identified, but it is still impossible to isolate bona fide PDLSCs from PDL because a single specific marker for PDLSCs has not been identified as yet. To date, a combination of cell surface markers have been utilized to isolate the PDLSCs. In particular, STRO-1 ${ }^{9)}$ and CD146 have been used as markers for the selection of PDLSCs ${ }^{8,12,13)}$. In contrast, we have not been 
A

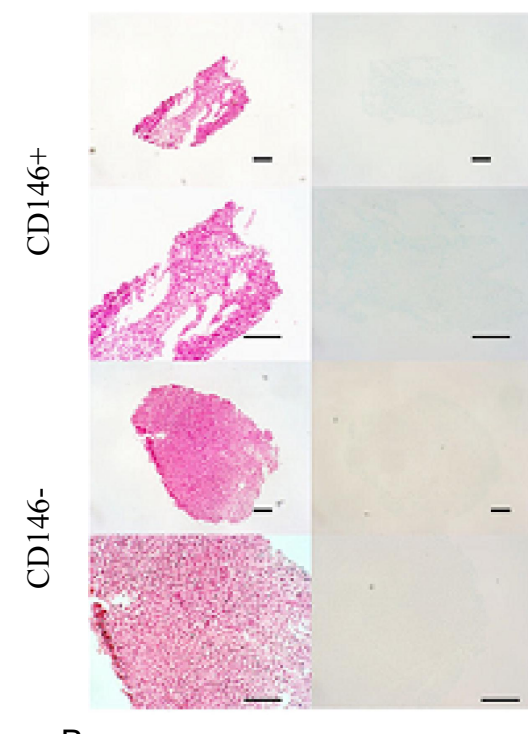

B

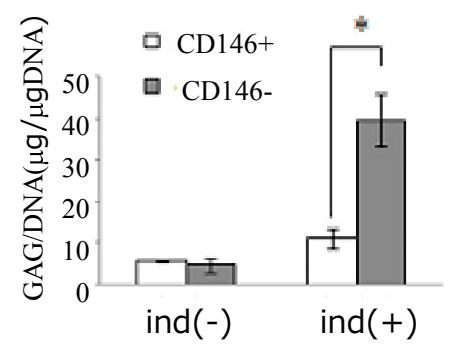

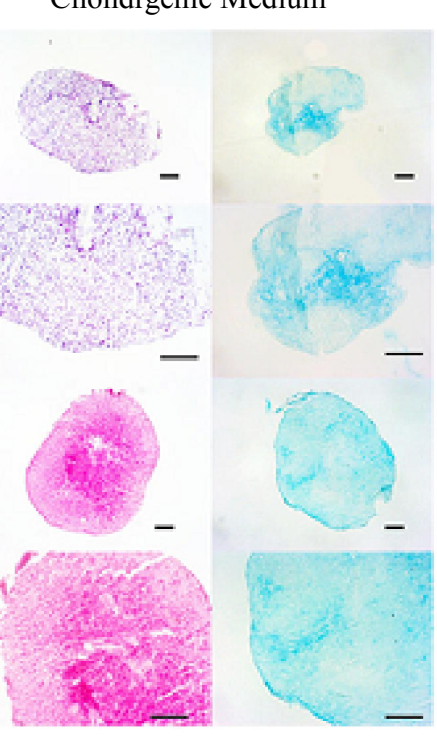

C

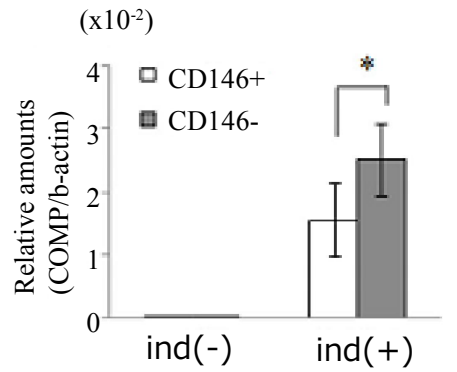

Figure 9. Chondrogenic differentiation potential

(A) Cells were cultured in a pellet and exposed to growth or chondrogenic medium for 28 days. The pellets were fixed, sectioned, and stained with H\&E or Alcian Blue. Images were captured under $20 \times$ and $40 \times$ magnification. Bar: $100 \mu \mathrm{m}(\mathrm{B})$ The GAG content of the pellets was measured. Each bars indicated the mean \pm standard deviation $(\mathrm{SD})\left(\mathrm{n}=6,{ }^{*} P<0.05\right)$ (C) The pellets were cultured in growth medium (ind (-)) or chondrogenic medium (ind (+)) for 7 days and mRNAs were extracted. Real-time PCR was used to analyze mRNA expression of the indicated chondrogenic marker (COMP). Each bars indicated the mean \pm standard deviation $(\mathrm{SD})\left(\mathrm{n}=3,{ }^{*} P<0.05\right)$.

able to detect STRO-1 expression in PDL cells, which is consistent with other reports ${ }^{25,26)}$.

In this study, we investigated the utility of CD146 as surface maker to isolate the required subset of PDLSCs. CD146/MCAM has been shown to play a role in cell-to-cell adhesion ${ }^{27-31)}$. The function of CD146 in lymphocytes has been demonstrated through the interaction of MCAM-1 with the actin cytoskeleton, which leads to the formation of microvilli ${ }^{11,32,33)}$. In contrast, the function of CD146 in PDLSCs is relatively poorly understood and its suitability as a PDLSCs marker has not been established. In order to characterize CD146 in PDLSCs, we investigated sorted cells with higher intensity of CD146 expression $\left(\mathrm{CD} 146^{+}\right.$cells) and those with lower intensity of CD146 expression (CD146- cells).

The average proportion of CD $146^{+}$cells in PDL from ten patients was approximately 50 “, but there was some interindividual variability. Previous studies have found that the proportion of $\mathrm{CD} 146^{+}$cells in PDL varied from $21 \%{ }^{34)}$ to $60 \%{ }^{13)}$, and they were $37 \%$ in HUVEC, $66 \%$ in pericytes, and $73 \%$ in MSC from bone marrow ${ }^{35)}$. In this study, the stability of CD146 expression was examined after culture for 30 days and 50 days. After the $\mathrm{CD} 146^{+}$cells were sorted and cultured for 30 days with one passage in growth medium, the proportion of $\mathrm{CD} 146^{+}$cells remained over $80 \%$ and the cultured cells were pre-confluent. At day 50 , the proportion of $\mathrm{CD} 146^{+}$was greatly decreased to $50 \%$ and the cultured cells were over-confluent. These results suggest that the condition of the cultured cells influences CD146 expression in PDL cells. Furthermore, after the sorted CD146 cells were passaged three times while they were under $50 \%$ confluence, the proportion of CD $146^{+}$cells was maintained at over $90 \%$ with only one sample that lost CD146 expression (data not shown). In contrast, the proliferation activity of CD146 cells was greatly decreased after several passages (data not shown). These results suggest that the CD146 expression is regulated during cell growth in hPDL cells, but this study did not directly investigate 
that process.

Surprisingly, this study showed for the first time that CD146 cells could be detected in three out of ten cell cultures that were originally isolated as CD146- cells. These data suggest that CD146cells are capable of converting to $\mathrm{CD} 146^{+}$cells. The regulation of CD146 antigen expression in long-term cultures of PDL cells is poorly understood but it has been shown that long-term culture affects the expression level of surface markers in bone marrowderived $\mathrm{MSC}^{36-38)}$. The detachment of PDL cells from their in vitro niche may result in a change in their environment at the maturation stage, which consequently induces CD146 expression ${ }^{39}$. Recently, a new concept has been suggested that the state of "stemness" may be transient and reversible rather than a fixed property that develops following interaction with the environment ${ }^{40-42)}$. This concept is applicable to PDLSCs obtained in this study as a fundamental property of MSCs.

A previous report demonstrated that cellular clonogenic potential is highly correlated with the percentage of CD146 ${ }^{+}$cells in the culture ${ }^{43}$. Because the present study showed that CD146cells also possess replicative potential, the $\mathrm{CD}^{146^{-}}$cell population may contain cells with the properties of MSC although the proportion of cells with MSC properties is lower than in the CD146 ${ }^{+}$cell population.

A basic criterion that defines MSC is the possession of trilineage potential to exhibit osteogenesis, adipogeneis, and chondrogenesis ${ }^{44}$. MSC can either lose multi-lineage potential during in vitro culture or maintain this potential ${ }^{45}$. In this study, we examined the tri-lineage potential properties of PDL cells. In agreement with previous studies, $\mathrm{CD} 146^{+}$cells were able to undergo osteogenic, chondrogenic, and adipogenic differentiation ${ }^{13)}$. Surprisingly, CD146- cells also demonstrated trilineage differentiation potential in this study, but the efficiency of osteogenic differentiation in CD146- cells was lower than CD146 ${ }^{+}$ cells. In addition, there were scarcely any cells with positive Oil Red O-staining in the CD146- cell culture. In contrast, the GAG secretion analysis indicated that the chondrogenic differentiation potential of CD146- cells was higher than $\mathrm{CD}^{-} 46^{+}$cells. Previous studies have described that adiopogenic differentiation potential is the first to be eliminated and it is followed by the loss of chondrogenic differentiation potential, with the retention of osteogenic differentiation potential ${ }^{46)}$. In the human hematopoietic system and the MSC population, cells are characterized by a hierarchical organization of differentiation potential ${ }^{46-49}$. Within this hierarchy, using our culture conditions, putative PDLSCs within the $\mathrm{CD} 146^{+}$cell population exhibited bi-potent, osteogenicchondrogenic potential in major proportion. On the other hand, putative PDLSCs within the CD146 cell population exhibited unipotent, chondrogenic potential in major proportion. However, this study cannot propose that the tripotent PDLSCs give rise to bipotent PDLSCs or uni-potent followed by a loss of adipogenesis.
Taken together, for the first time, PDLSCs with tri-lineage differentiation potential are included in the CD146- cell population although most PDLSCs show uni-potent differentiation.

The stability of CD146 expression was examined when cells were cultured in either osteogenic or adipogenic medium. CD146 expression may be maintained at over $20 \%$ in the differentiation medium, but lost in growth medium, because cell aggregation has already occurred in the culture, which was over-confluence in growth medium for 21 days. Therefore, confluence may lead to the loss of CD146 expression in PDL cells. MSCs divide asymmetrically and generate a replica daughter cell as well as a transient amplifying cell with multi-potency ${ }^{50)}$. Our experimental data suggest that the environment in differentiation medium may support the asymmetrical dividing of PDLSCs, which results in the production of $\mathrm{CD} 146^{+}$cells through the self-renewal potential of these cells.

This study examined the utility of CD146 expression in hPDL cells and showed that the CD146 marker is indeed useful for isolating cells with osteogenic or chondrogenic potential. Our results raise another major question. Is using either $\mathrm{CD} 146^{+}$or CD146- cells preferable for PDL regeneration? PDLSCs need to produce either non-calcified PDL or calcified tissues such as cementum and bone. Therefore, we are attempting to transplant both cell populations into PDL defects to answer this question. The findings from these studies will support the potential utility of PDLSCs for cell-based therapeutic applications.

\section{Acknowledgments}

This work was supported in part by Grant-in-Aid for Scientific Research (B) (21390528 \& 24390447 to MH), and Grants-in-Aid for Young Scientists (B) (24792311 to KM), and Nihon University Research Grant for 2011 and 2012 (MH).

\section{References}

1. Pihlstrom BL, Michalowicz BS and Johnson NW. Periodontal diseases. Lancet 366:1809-1820, 2005

2. Wang HL, Greenwell H, Fiorellini J, Giannobile W, Offenbacher S, Salkin L, Townsend C, Sheridan P and Genco RJ. Periodontal regeneration. J Periodontol 76: 1601-1622, 2005

3. Bartold PM, McCulloch CA, Narayanan AS and Pitaru S. Tissue engineering: a newparadigm for periodontal regeneration based on molecular and cell biology. Periodontol 2000 24: 253-269, 2000

4. Shimono M, Ishikawa T, Ishikawa H, Matsuzaki H, Hashimoto S, Muramatsu T, Shima K, Matsuzaka K and Inoue $\mathrm{T}$. Regulatory mechanisms of periodontal regeneration. Microsc Res Tech 60: 491-502, 2003

5. McCulloch CA. Progenitor cell populations in the periodontal ligament of mice. Anat Rec 211: 258-262, 1985 
Yoko Saito et al.: CD146 Marker for PDL

6. McCulloch CA. Basic considerations in periodontal wound healing to achieve regeneration. Periodontol 2000 1: 16-25, 1993

7. McCulloch CA and Melcher AH. Continuous labelling of the periodontal ligament of mice. J Periodontal Res 18: 231241, 1983

8. Seo BM, Miura M, Gronthos S, Bartold PM, Batouli S, Brahim J, Young M, Robey PG, Wang CY and Shi S. Investigation of multipotent postnatal stem cells from human periodontal ligament. Lancet 364: 149-155, 2004

9. Simmons PJ and Torok-Storb B. Identification of stromal cell precursors in human bone marrow by a novel monoclonal antibody, STRO-1. Blood 78: 55-62, 1991

10. Kemoun P, Gronthos S, Snead ML, Rue J, Courtois B, Vaysse F, Salles JP and Brunel G. The role of cell surface markers and enamel matrix derivatives on human periodontal ligament mesenchymal progenitor responses in vitro. Biomaterials 32: 7375-7388, 2011

11. Guezguez B, Vigneron P, Lamerant N, Kieda C, Jaffredo T and Dunon D. Dual role of melanoma cell adhesion molecule (MCAM)/CD146 in lymphocyte endothelium interaction: MCAM/CD146 promotes rolling via microvilli induction in lymphocyte and is an endothelial adhesion receptor. $\mathrm{J}$ Immunol 179: 6673-6685, 2007

12. Chen SC, Marino V, Gronthos S and Bartold PM. Location of putative stem cells in human periodontal ligament. J Periodontal Res 41: 547-553, 2006

13. Xu J, Wang W, Kapila Y, Lotz J and Kapila S. Multiple differentiation capacity of STRO-1+/CD146+ PDL mesenchymal progenitor cells. Stem Cells Dev 18: 487-496, 2009

14. Yoshida T, Washio K, Iwata T, Okano T and Ishikawa I. Current status and future development of cell transplantation therapy for periodontal tissue regeneration. Int J Dent 2012: 307024, 2012

15. Washio K, Iwata T, Mizutani M, Ando T, Yamato M, Okano $\mathrm{T}$ and Ishikawa I. Assessment of cell sheets derived from human periodontal ligament cells: a pre-clinical study. Cell Tissue Res 341: 397-404, 2010

16. Mikami $Y$, Ishii $Y$, Watanabe $N$, Shirakawa T, Suzuki S, Irie S, Isokawa K and Honda MJ. CD271/p75(NTR) inhibits the differentiation of mesenchymal stem cells into osteogenic, adipogenic, chondrogenic, and myogenic lineages. Stem Cells Dev 20: 901-913, 2011

17. Yang Z, Jin F, Zhang X, Ma D, Han C, Huo N, Wang Y, Zhang Y, Lin Z and Jin Y. Tissue engineering of cementum/ periodontal-ligament complex using a novel threedimensional pellet cultivation system for human periodontal ligament stem cells. Tissue Eng Part C Methods 15: 571581,2009
18. Kawaguchi H, Hirachi A, Hasegawa N, Iwata T, Hamaguchi H, Shiba H, Takata T, Kato Y and Kurihara H. Enhancement of periodontal tissue regeneration by transplantation of bone marrow mesenchymal stem cells. J Periodontol 75: 12811287, 2004

19. McBeath R, Pirone DM, Nelson CM, Bhadriraju K and Chen CS. Cell shape, cytoskeletal tension, and RhoA regulate stem cell lineage commitment. Dev Cell 6: 483-495, 2004

20. Itaya T, Kagami H, Okada K, Yamawaki A, Narita Y, Inoue M, Sumita Y and Ueda M. Characteristic changes of periodontal ligament-derived cells during passage. J Periodontal Res 44: 425-433, 2009

21. Tsuchiya S, Ohshima S, Yamakoshi Y, Simmer JP and Honda MJ. Osteogenic differentiation capacity of porcine dental follicle progenitor cells. Connect Tissue Res 51: 197-207, 2010

22. Ito Y, Toriuchi N, Yoshitaka T, Ueno-Kudoh H, Sato T, Yokoyama S, Nishida K, Akimoto T, Takahashi M, Miyaki $\mathrm{S}$ and Asahara $\mathrm{H}$. The Mohawk homeobox gene is a critical regulator of tendon differentiation. Proc Natl Acad Sci USA 107: 10538-10542, 2010

23. Akizuki T, Oda S, Komaki M, Tsuchioka H, Kawakatsu N, Kikuchi A, Yamato M, Okano T and Ishikawa I. Application of periodontal ligament cell sheet for periodontal regeneration: a pilot study in beagle dogs. J Periodontal Res 40: 245-251, 2005

24. Hasegawa M, Yamato M, Kikuchi A, Okano T and Ishikawa I. Human periodontal ligament cell sheets can regenerate periodontal ligament tissue in an athymic rat model. Tissue Eng 11: 469-478, 2005

25. Fukushima H, Kawanabe N, Murata S, Ishihara Y, Yanagita T, Balam TA and Yamashiro T. SSEA-4 is a Marker of Human Deciduous Periodontal Ligament Stem Cells. J Dent Res 91: 955-960, 2012

26. Colter DC, Sekiya I and Prockop DJ. Identification of a subpopulation of rapidly self-renewing and multipotential adult stem cells in colonies of human marrow stromal cells. Proc Natl Acad Sci U S A 98: 7841-7845, 2001

27. Lehmann JM, Riethmuller G and Johnson JP. MUC18, a marker of tumor progression in human melanoma, shows sequence similarity to the neural cell adhesion molecules of the immunoglobulin superfamily. Proc Natl Acad Sci U S A 86: 9891-9895, 1989

28. Sers C, Kirsch K, Rothbacher U, Riethmuller G and Johnson JP. Genomic organization of the melanoma-associated glycoprotein MUC18: implications for the evolution of the immunoglobulin domains. Proc Natl Acad Sci U S A 90: 8514-8518, 1993

29. Vainio O, Dunon D, Aissi F, Dangy JP, McNagny KM and Imhof BA. HEMCAM, an adhesion molecule expressed by 
c-kit+ hemopoietic progenitors. J Cell Biol 135: 1655-1668, 1996

30. Taira E, Kohama K, Tsukamoto Y, Okumura S and Miki N. Characterization of Gicerin/MUC18/CD146 in the rat nervous system. J Cell Physiol 198: 377-387, 2004

31. Taira E, Kohama K, Tsukamoto Y, Okumura S and Miki N. Gicerin/CD146 is involved in neurite extension of NGFtreated PC12 cells. J Cell Physiol 204: 632-637, 2005

32. Okumura S, Muraoka O, Tsukamoto Y, Tanaka H, Kohama $\mathrm{K}$, Miki $\mathrm{N}$ and Taira E. Involvement of gicerin in the extension of microvilli. Exp Cell Res 271: 269-276, 2001

33. Bardin N, Anfosso F, Masse JM, Cramer E, Sabatier F, Le Bivic A, Sampol J and Dignat-George F. Identification of CD146 as a component of the endothelial junction involved in the control of cell-cell cohesion. Blood 98: 3677-3684, 2001

34. Park JC, Kim JM, Jung IH, Kim JC, Choi SH, Cho KS and Kim CS. Isolation and characterization of human periodontal ligament (PDL) stem cells (PDLSCs) from the inflamed PDL tissue: in vitro and in vivo evaluations. J Clin Periodontol 38: 721-731, 2011

35. Covas DT, Panepucci RA, Fontes AM, Silva WA, Jr., Orellana MD, Freitas MC, Neder L, Santos AR, Peres LC, Jamur MC and Zago MA. Multipotent mesenchymal stromal cells obtained from diverse human tissues share functional properties and gene-expression profile with CD146+ perivascular cells and fibroblasts. Exp Hematol 36: 642-654, 2008

36. Wagner W, Horn P, Castoldi M, Diehlmann A, Bork S, Saffrich R, Benes V, Blake J, Pfister S, Eckstein V and Ho AD. Replicative senescence of mesenchymal stem cells: a continuous and organized process. PLoS One 3: e2213, 2008

37. Stolzing A, Jones E, McGonagle D and Scutt A. Age-related changes in human bone marrow-derived mesenchymal stem cells: consequences for cell therapies. Mech Ageing Dev 129: 163-173, 2008

38. Le Blanc K, Samuelsson H, Lonnies L, Sundin M and Ringden O. Generation of immunosuppressive mesenchymal stem cells in allogeneic human serum. Transplantation 84: 1055-1059, 2007

39. Wagner W, Ho AD and Zenke M. Different facets of aging in human mesenchymal stem cells. Tissue Eng Part B Rev 16: 445-453, 2010

40. Zipori D. The stem state: plasticity is essential, whereas self-renewal and hierarchy are optional. Stem Cells 23: 719726, 2005

41. Zipori D. The stem state: mesenchymal plasticity as a paradigm. Curr Stem Cell Res Ther 1: 95-102, 2006

42. Zipori D. Mesenchymal stem cells: harnessing cell plasticity to tissue and organ repair. Blood Cells Mol Dis 33: 211215,2004

43. Russell KC, Phinney DG, Lacey MR, Barrilleaux BL, Meyertholen KE and O'Connor KC. In vitro high-capacity assay to quantify the clonal heterogeneity in trilineage potential of mesenchymal stem cells reveals a complex hierarchy of lineage commitment. Stem Cells 28: 788-798, 2010

44. Dominici M, Le Blanc K, Mueller I, Slaper-Cortenbach I, Marini F, Krause D, Deans R, Keating A, Prockop D and Horwitz E. Minimal criteria for defining multipotent mesenchymal stromal cells. The International Society for Cellular Therapy position statement. Cytotherapy 8: 315 317, 2006

45. Pittenger MF, Mackay AM, Beck SC, Jaiswal RK, Douglas R, Mosca JD, Moorman MA, Simonetti DW, Craig S and Marshak DR. Multilineage potential of adult human mesenchymal stem cells. Science 284: 143-147, 1999

46. Muraglia A, Cancedda R and Quarto R. Clonal mesenchymal progenitors from human bone marrow differentiate in vitro according to a hierarchical model. J Cell Sci 113 ( Pt 7): 1161-1166, 2000

47. Charbord P, Oostendorp R, Pang W, Herault O, Noel F, Tsuji T, Dzierzak E and Peault B. Comparative study of stromal cell lines derived from embryonic, fetal, and postnatal mouse blood-forming tissues. Exp Hematol 30: 1202-1210, 2002

48. Banfi A, Muraglia A, Dozin B, Mastrogiacomo M, Cancedda $\mathrm{R}$ and Quarto R. Proliferation kinetics and differentiation potential of ex vivo expanded human bone marrow stromal cells: Implications for their use in cell therapy. Exp Hematol 28: 707-715, 2000

49. Sarugaser R, Hanoun L, Keating A, Stanford WL and Davies JE. Human mesenchymal stem cells self-renew and differentiate according to a deterministic hierarchy. PLoS One 4: e6498, 2009

50. Phinney DG. Biochemical heterogeneity of mesenchymal stem cell populations: clues to their therapeutic efficacy. Cell Cycle 6: 2884-2889, 2007 